\title{
DEVELOPMENT OF POSTERIOR CAPSULAR OPACIFICATION POST-OPERATIVELY IN CATARACT SURGERY USING DIFFERENT TECHNIQUES AND DIFFERENT INTRAOCULAR LENSES
}

\author{
Smita Javadekar ${ }^{1}$
}

${ }^{1}$ Professor and HOD, Department of Ophthalmology, Prakash Institute of Medical Sciences and Research, Islampur, Maharashtra.

\begin{abstract}
\section{BACKGROUND}

With accurate estimation of power of Intraocular Lens (IOL), uncomplicated cataract surgery and uneventful post-operative period, the implant is capable of providing a visual acuity of 6/6 and a normal field of vision. However, post-operative results are not always according to the expectations. Among all the causes of subnormal vision, Posterior Capsular Opacification (PCO) is one of the common cause of subnormal vision postoperatively. This study is an attempt to find out causes of posterior capsular opacification in an uneventful cataract surgery with posterior chamber intraocular lens by various surgical techniques and using different intraocular lenses in Krishna Institute of Medical Sciences, Karad and Prakash Institute of Medical Science and Research, Islampur.

The aims of this study are to study the incidence of posterior capsular opacification in patients who have undergone uneventful cataract surgery with posterior chamber IOL implant and relation between the type of surgery and IOL used and its effect on the subnormal vision post-operatively due to posterior capsular opacification, also to find out other causes of subnormal vision 6 weeks post-operatively in an uneventful cataract surgery in Krishna Hospital over a period of 13 months and in Prakash Institute of Medical Science and Research, Islampur over a period of 5 months
\end{abstract}

\section{MATERIALS AND METHODS}

183 patients among 1290 who underwent uneventful cataract surgery were diagnosed to have posterior capsular opacification in our study over the period of 18 months. All pseudophakic patients, who underwent uneventful cataract surgery with normal preoperative assessment were included in the study. Diabetic and hypertensive patients without any maculopathy were also included. Patients with intra operative complications, traumatic cataract, complicated cataract and pre-existing pathology were excluded.

\section{RESULTS}

Incidence of Posterior Capsular Opacification (PCO) was 80.87\%. Incidence of PCO was least in foldable IOLs as compared to Square Edge and Non-Square Edge. Other causes of subnormal vision were Cystoid Macular Oedema, Diabetic Macular Oedema, Malposition of IOL, Toxic Anterior Segment Syndrome and Endophthalmitis.

\section{CONCLUSION}

Foldable intraocular lenses have lowest incidence of PCO. In case of non-foldable intraocular lenses, square edge lenses have lower incidence of PCO. Phacoemulsification gives lower incidence of PCO than small incision cataract surgery.

\section{KEYWORDS}

Subnormal Vision, Posterior Chamber IOL, Pseudophakic, Posterior Capsular Opacification.

HOW TO CITE THIS ARTICLE: Javadekar S. Development of posterior capsular opacification post-operatively in cataract surgery using different techniques and different intraocular lenses. J. Evolution Med. Dent. Sci. 2017;6(2):103-105, DOI: $10.14260 /$ Jemds/2017/26

\section{BACKGROUND}

The history of Intraocular Lens (IOL) implantation has been a long saga of excitement and the ultimate outcome has been rewarding. Sir Harold Ridley performed the first IOL implant in the posterior chamber of the left eye of a 45 years old woman after an Extracapsular Cataract Extraction on 24th November 1949 at St. Thomas Hospital, ${ }^{1}$ London. Since then there has been a number of changes in surgical techniques, lens design, lens material, lens sterilisation and placement of IOL. Further advances in cataract surgery like Phacoemulsification, Microsurgery and newer IOLs like Toric

Financial or Other, Competing Interest: None.

Submission 29-11-2016, Peer Review 22-12-2016,

Acceptance 29-12-2016, Published 05-01-2017.

Corresponding Author:

Dr. Smita Javadekar,

Alchemy, Near Dandekar \& Co.

Vishrambag, Sangli-416415.

E-mail: smita10157@yahoo.co.in

DOI: $10.14260 / \mathrm{jemds} / 2017 / 26$ lens, Foldable lens, Multifocal lens, Square edge lens, the quality of vision and post-operative results have further improved. One of the most important advances in ophthalmology is phacoemulsification introduced by Charles C. Kelman in 1967. Extracapsular Cataract Extraction (ECCE) requires a relatively large wound that results in a long healing process, induced astigmatism, slow visual recovery and the potential for endophthalmitis. Phacoemulsification requires a smaller surgical wound resulting in a shorter healing process, less against-the-rule astigmatism and more rapid visual recovery.

This study is an attempt to find the Incidence of Posterior Capsular Opacification (PCO) amongst patients who underwent uneventful extracapsular cataract extraction with posterior chamber intraocular lens by various surgical techniques and different types of intraocular lenses. Along with it also to find out other causes of subnormal vision 6 weeks postoperatively in an uneventful cataract surgery. 


\section{MATERIALS AND METHODS}

183 patients out of 1290 uneventful cataract surgeries performed were diagnosed to have PCO after uneventful surgery over the period of 18 months and were included in the study. It is a retrospective cohort study.

Inclusion criteria include all pseudophakic patients who have undergone uneventful cataract surgery with normal pre-operative assessment. "By uneventful cataract surgery we mean no intraoperative complications, which can affect the outcome of surgery and result in subnormal vision."

Diabetic and hypertensive patients without any maculopathy who have undergone uneventful cataract surgery were included in the study.

Patients with intraoperative complications, other ocular pathology like corneal opacity, traumatic cataract, complicated cataract, trauma post-operatively and any pathology on fundus and macula, which can result in subnormal vision were excluded from our study.

For every patient, a detailed pre-operative evaluation was done. Best visual correction was noted and ocular examination with slit lamp, direct and indirect ophthalmoscope was done. In cases of media opacity where details of the fundus were not clear special investigations like B-Scan, Maddox rod test were done to rule out any maculopathy and other retinal pathology.

Post-operatively, patients were followed up till $6^{\text {th }}$ week post-op day and on $6^{\text {th }}$ week slit lamp examination for PCO and refraction was done. Patients having PCO on slit lamp examination and with best corrected vision $<6 / 9$ were included in the study. Those patients who had normal vision at $6^{\text {th }}$ week post-op, but developed subnormal vision and PCO later during the duration of the study were also included in the study.

\section{RESULTS}

Total no. of uneventful cataract surgeries done during the study period were 1290, out of which 1154 were Small Incision Cataract Surgery (SICS) and 136 were phacoemulsification (Phaco). In 18 months of study, 148 patients were diagnosed with subnormal vision due to PCO 6 weeks postoperatively. Statistical analysis was done as per requirement using Chi-square test of significance. ( $\mathrm{P}$ value less than 0.05 is considered as significant).

\begin{tabular}{|c|c|c|c|c|c|}
\hline Type of IOL & PCO & $\begin{array}{l}\text { Non- } \\
\text { PCO }\end{array}$ & Total & $\begin{array}{l}\text { \% of } \\
\text { PCO }\end{array}$ & $\begin{array}{c}P \\
\text { Value }\end{array}$ \\
\hline Square Edge & 15 & 273 & 266 & $5.63 \%$ & \multirow{4}{*}{0.000} \\
\hline Non-Square Edge & 130 & 736 & 866 & $15.01 \%$ & \\
\hline Foldable & 3 & 133 & 136 & $2.20 \%$ & \\
\hline Total & 148 & 1142 & 1290 & $11.47 \%$ & \\
\hline
\end{tabular}

Incidence of PCO is least in Acrylic foldable (2.20\%) as compared to Square Edge (5.63\%) and Non-Square Edge (15.01). Among Square Edge and Non-Square Edge, incidence is less in Square Edge IOLs. Incidence of PCO was significantly low in Phaco than SICS, as the P value is $<0.05$.

Other causes of subnormal vision were Cystoid Macular Oedema, Diabetic Macular Oedema, Malposition of IOL, Toxic Anterior Segment Syndrome and Endophthalmitis.

\begin{tabular}{|c|c|}
\hline Type of Surgery & PCO \\
\hline SICS & 145 \\
\hline Phaco & 3 \\
\hline Total & 148 \\
\hline P value & 0.0438 \\
\hline $\begin{array}{c}\text { Table 2. Relation between Type of } \\
\text { Surgery and Incidence of PCO }\end{array}$ \\
\hline
\end{tabular}

\begin{tabular}{|c|c|c|}
\hline Causes & No. of Cases & $\mathbf{\%}$ \\
\hline PCO & 148 & 80.87 \\
\hline CME & 17 & 9.28 \\
\hline Malposition of IOL & 13 & 7.10 \\
\hline DME & 5 & 2.73 \\
\hline TASS & 1 & 0.54 \\
\hline Table 3. Other Causes of Subnormal Vision along with PCO
\end{tabular}

\begin{tabular}{|c|c|c|c|c|c|c|c|}
\hline $\begin{array}{c}\text { Type of } \\
\text { Surgery }\end{array}$ & PCO & CME & DME & $\begin{array}{c}\text { Mal- } \\
\text { Position }\end{array}$ & TASS & Endoph & Total \\
\hline SICS & 145 & 11 & 3 & 13 & 1 & 1 & 174 \\
\hline Phaco & 3 & 6 & 2 & 0 & 0 & 0 & 11 \\
\hline Total & $\mathbf{1 4 8}$ & $\mathbf{1 7}$ & $\mathbf{5}$ & $\mathbf{1 3}$ & $\mathbf{1}$ & $\mathbf{1}$ & $\mathbf{1 8 5}$ \\
\hline P value & 0.0438 & 0.00 & 0.0013 & 0.36464 & 0.8015 & 0.8015 & \\
\hline \multicolumn{7}{c|}{ Table 4. Relation between Type of Surgery } \\
and Causes of Subnormal Vision \\
\hline
\end{tabular}

\section{DISCUSSION}

Causes of subnormal vision 6 weeks post-operatively found were PCO, Cystoid Macular Oedema, Diabetic Macular Oedema, Malposition of IOL, Toxic Anterior Segment Syndrome and Endophthalmitis.

Incidence of subnormal vision 6 weeks post-operatively was highest in cases of patients with non-square edge IOLs followed by square edge and foldable lenses. It can be due to the fact that non-square edge PMMA (Polymethylmethacrylate) lenses are associated with high rate of PCO.

The commonest cause of subnormal vision post uneventful cataract surgery in our study was PCO (80.87\%). This is because of high number of non-square edge lenses used in cataract surgery in our study. Non-square edge lenses are still used in great number in developing countries because of their low cost.

Incidence of PCO was higher in SICS (14.99\%) as compared to phacoemulsification (7.35\%). The high incidence of PCO in SICS was may be because of the high volume of SICS surgeries done in the Institutes than phacoemulsification. As SICS is machine independent and cost effective, it is preferred in developing countries like India.

Second commonest cause of subnormal vision after uneventful cataract surgery was Cystoid Macular Oedema (9.28\%). This result is similar to other studies done by Hiranmoyee et al. ${ }^{2}$ In their study, the rate of CME was $6.67 \%$.

The third commonest cause was malposition of IOL. Out of 13 cases of malposition of IOL, haptics of 8 IOLs were in sulcus, in 4 cases one haptic was in bag and other in the sulcus and in 1 case both haptics were in bag, but there was zonular weakness. It has been seen that one haptic in sulcus and another in bag causes tilting of IOL, which causes high astigmatism. $^{3}$ 
Total no. of diabetic patients with subnormal vision was 44, of which 5 patients showed clinically significant diabetic macular oedema post-cataract surgery. These diabetic patients showed increase in thickness at the macular area on OCT, post-cataract surgery. Studies have shown that there occurs increase in severity of diabetic retinopathy postcataract surgery due to intraocular inflammation. ${ }^{4}$

Rate of toxic anterior segment syndrome and delayed endophthalmitis was $0.54 \%$ each. TASS occurs most commonly following cataract surgery, but may occur following anterior segment surgeries of any kind including glaucoma or cornea transplant surgeries. The aetiology of TASS is relatively broad and may include problems involving irrigating solutions, such as Balanced Saline Solution (BSS) and any additives included.5-9

Highest number of cases of PCO were in patients with non-square edge lenses as compared to square edge lens and foldable lens. The reason for low incidence of PCO in square edge and foldable lenses is because of the unique IOL design. Square edge design acts as a barrier preventing the migration of lens, epithelial cells from the equatorial region onto the posterior capsule. ${ }^{10}$

In our study, incidence of PCO is least with foldable lenses. This is similar to one study done by Hassan Hashemi et al, which suggested that rate of PCO is more with PMMA lenses as compared with foldable lenses. ${ }^{11}$ There is another study, which shows that there was no significant difference in the PCO between the square edged PMMA and square edged foldable lens. ${ }^{12}$

Incidence of PCO, CME and DME are significantly low in phacoemulsification than SICS and the incidence of malposition of IOL, TAS and endophthalmitis is not significant.

\section{CONCLUSION}

This Study Reached on Following Conclusions

- In our study Phacoemulsification proves to be a better option of cataract extraction.

- $\quad$ Square edge design IOLs helps in preventing early PCO.

- Foldable IOLs implantation is preferable to PMMA nonfoldable IOLs.

- Confirmation of IOL in the bag is mandatory intraoperatively to prevent subluxation of IOL.
- Other causes of subnormal vision were Cystoid Macular Oedema, Diabetic Macular Oedema, Malposition of IOL, Toxic Anterior Segment Syndrome and Endophthalmitis.

\section{REFERENCES}

[1] Ridley H. Intra-ocular acrylic lenses; a recent development in the surgery of cataract. $\mathrm{Br}$ J Ophthalmol 1952;36(3):113-22.

[2] Das H, Goswami PK, Barua CK. Cause of nonimprovement of vision in Pseudophakic eye. Caduceus 2008:3-7.

[3] Kanellopoulos AJ, Papakostas TD. Malpositioned IOLs: etiology, prevention and management. Cataract \& Refractive Surgery Today Europe 2008;70-2.

[4] Farah SE. The impact of cataract surgery on preexisting retinal diseases. EyeNet Magazine (AAO) 2010:41-3.

[5] Swan KC. Reactivity of the ocular tissues to wetting agents. Am J Ophthalmol 1944;27(10):1118-22.

[6] Edelhauser HF, Van Horn DL, Schultz RO, et al. Comparative toxicity of intraocular irrigating solutions on the corneal endothelium. Am J Ophthal 1976;81(4):473-81.

[7] Gonnering R, Edelhauser HF, Van Horn DL, et al. The $\mathrm{pH}$ tolerance of rabbit in human corneal endothelium. Inv Ophthalmol Vis Sci 1979;18(4):373-90.

[8] Edelhauser HF, Hanneken AM, Pederson HJ, et al. Osmotic tolerance of rabbit in human corneal endothelium. Arch Ophthalmol 1981;99(7):1281-7.

[9] Parikh CH, Edelhauser HF. Ocular surgical pharmacology: corneal endothelial safety and toxicity. Curr Opin Ophthalmol 2003;14(4):178-85.

[10] Izak AM, Werner L, Pandey SK, et al. Pathological evaluation of postmortem human eyes implanted with a new single-piece hydrophobic acrylic lens. J Cataract Refract Surg 2004;30(7):1537-44.

[11] Hashemi H, Mohammadi SF, Majdi M, et al. Posterior capsule opacification after cataract surgery and its determinants. Iranian Journal of Ophthalmology 2012;24(2):3-8.

[12] Hazra S, Palui H, Vemuganti GK. Comparison of design of intraocular lens versus the material for PCO prevention. Int J Ophthalmol 2012;5(1):59-63. 